\title{
Atlantic Control of the Late Nineteenth-Century Sahel Humid Period
}

\author{
JULIÁN VILLAMAYOR \\ Universidad Complutense de Madrid, and Instituto de Geociencias, Madrid, Spain \\ ELSA MOHINO \\ Universidad Complutense de Madrid, Madrid, Spain \\ Myriam Khodri, Juliette Mignot, AND Serge JANicot \\ LOCEAN/IPSL, Sorbonne Universités, UPMC-CNRS-IRD-MNHN, Paris, France
}

(Manuscript received 13 March 2018, in final form 16 July 2018)

\begin{abstract}
Precipitation regime shifts in the Sahel region have dramatic humanitarian and economic consequences such as the severe droughts during the 1970s and 1980s. Though Sahel precipitation changes during the late twentieth century have been extensively studied, little is known about the decadal variability prior to the twentieth century. Some evidence suggests that during the second half of the nineteenth century, the Sahel was as rainy as or even more rainy than during the 1950s and 1960s. Here, we reproduce such an anomalous Sahel humid period in the late nineteenth century by means of climate simulations. We show that this increase of rainfall was associated with an anomalous supply of humidity and higher-than-normal deep convection in the mid- and high troposphere. We present evidence suggesting that sea surface temperatures (SSTs) in the Atlantic basin played the dominant role in driving decadal Sahel rainfall variability during this early period.
\end{abstract}

\section{Introduction}

The Sahel is the semiarid zonal fringe of West Africa lying between the Sahara Desert to the north and the tropical rainy savanna to the south $\left(10^{\circ}-17.5^{\circ} \mathrm{N}\right)$. This region is extremely sensitive to rainfall changes during its rainy season, which goes from July to September (JAS). Throughout the twentieth century, the Sahel experienced an abrupt change of its precipitation regime. It went from a sequence of mostly rainy years in the mid-twentieth century, over the 1950 s and 1960 s, to a long period, between the 1970s and 1980s, during which severe drought years predominated. In turn, there has been a recovery of the Sahel precipitation during the last decade of the twentieth century (Lebel and Ali 2009). Considering the precariousness of the countries in the Sahel and the climatic characteristics of the region itself, it is not surprising that such a change in the rainfall regime and the long persistence of drought conditions has had dramatic economic and humanitarian consequences

Corresponding author: Julián Villamayor, julian.villamayor@ ucm.es
(Ickowicz et al. 2012). The decadal variability of the Sahel rainfall during the twentieth century has therefore been the focus of a great number of research works (e.g., Folland et al. 1986; Giannini et al. 2003; Caminade and Terray 2010; Mohino et al. 2011a; Rodríguez-Fonseca et al. 2015). It is broadly agreed that changes in the West African Sahel rainfall rate at decadal time scales are induced by the SST variability in the Atlantic (Folland et al. 1986; Knight et al. 2006; Zhang and Delworth 2006; Ting et al. 2009; Martin and Thorncroft 2014), the Pacific, and the Indian Oceans (Bader and Latif 2003; Caminade and Terray 2010; Villamayor and Mohino 2015) and that these changes are amplified by land surface processes (Zeng and Neelin 1999; Giannini et al. 2003; Kucharski et al. 2013).

There are also many studies addressing the future evolution of the Sahel precipitation (Biasutti and Giannini 2006; Biasutti et al. 2008; Monerie et al. 2012; Biasutti 2013; Vizy et al. 2013). Two main competing factors have been identified to dominate these changes: the increasing trend of carbon dioxide atmospheric content and the global SST warming. The former tends to enhance the Sahel rainfall, while the latter tends to 
reduce it (Biasutti and Giannini 2006; Gaetani et al. 2017), with more pronounced effects in the central Sahel at the end of the rainy season and in the western Sahel at the start of the rainy season, respectively (Biasutti 2013). Forecasting these long-term trends would be very valuable in order to anticipate and prevent their negative impacts. In addition, great efforts have been made to develop reliable decadal predictions using general circulation models (Latif et al. 2004; Meehl et al. 2009; Doblas-Reyes et al. 2013). Their predictive skill has been related to their ability to correctly reproduce the link between SST and the Sahel precipitation (Gaetani and Mohino 2013; García-Serrano et al. 2015; Mohino et al. 2016). Therefore, having a good knowledge of the evolution of the Sahel rainfall in relation to the SST in the past is highly relevant for the understanding and assessment of future changes and decadal predictions.

Despite all the understanding of the West African monsoon (WAM) gathered in the instrumental period, there is very little documentation on the evolution of the Sahel precipitation during the nineteenth century. To our knowledge, the few existing sources that document this period are Gallego et al. (2015, hereafter GA15) and Nicholson et al. (2012, hereafter NI12). GA15 defines the so-called African southwesterly index (ASWI), based on the persistence of southwesterly low-level winds in a region over the Atlantic, close to West Africa $\left(29^{\circ}-17^{\circ} \mathrm{W}, 7^{\circ}-13^{\circ} \mathrm{N}\right)$, and calculated from historical measurements of JAS wind direction, complete since 1839. The ASWI is strongly correlated with the observed Sahel precipitation since 1900 and is, therefore, presented as a good indicator of its variability. NI12, in turn, made a semiquantitative reconstruction of rain in Africa during the nineteenth century. It is based on the use of descriptive documentary data of rainfall throughout the continent to complete the scarce information from rain gauge stations. To do this, the continent is divided into 90 regions with uniform precipitation regimes. Then, time series were defined, taking positive (negative) values from 1 to 3 depending on whether the year was moderately, abundantly, or severely rainy (dry) according to the documentation compiled at each region and following a selection criterion. The Sahel spans six of these regions, and its rainfall index is the average of their time series.

Both GA15 and NI12 have shown evidence of the existence of a humid period in the Sahel during some decades in the second half of the nineteenth century. However, they disagree as to the duration and intensity of this anomalously humid period. GA15 results suggest that it lasted from 1839 to 1890 and that it was more intense than the mid-twentieth-century rainy period. NI12 rather showed that in the second half of the nineteenth century, drought years predominated during 1855-64, followed by others with mostly wet conditions until 1892, although not excessively intense.

The key questions we want to address with this work are as follows: 1) Can the long rainy period of the late nineteenth century be reproduced with an atmospheric general circulation model (AGCM) forced with observed SSTs? 2) What are the atmospheric mechanisms that explain such a humid period, and what is their relation with the SST? 3) Which is the key basin controlling the Sahel decadal shifts in rainfall in the late nineteenth century?

\section{Data and methods}

\section{a. Observational data}

Different observational products are analyzed in this work. Monthly gridded data of precipitation from GPCC, version 7 (GPCC; Schneider et al. 2016), and Climatic Research Unit Time Series, version 3.24.01 [CRU TS3.24.01 (CRU); Harris et al. 2014], datasets, provided from 1901 to present with a spatial resolution of $0.5^{\circ}$ are used. Also the SST data from the HadISST, version 1 (HadISST1; Rayner et al. 2003), and ERSST. v4 (Huang et al. 2015; Liu et al. 2015) datasets, provided from 1870 to 1854 and with a spatial resolution of $1^{\circ}$ and $2^{\circ}$, respectively, are analyzed. Wind and specific humidity data from the NCEP reanalysis (Kalnay et al. 1996; providing data from 1948 with a latitude and longitude resolution of $2.5^{\circ}$ and 17 vertical levels) are used to calculate the moisture flux as the product between both and to represent the observed atmospheric dynamics. Finally, the observational ASWI of GA15 and the semiquantitative precipitation data from NI12 in the Sahel are also represented.

\section{b. LMDZ model and experimental design}

The simulations performed in this work have been done with the fifth version of the Laboratoire de Météorologie Dynamique zoom model (LMDZ). This AGCM is developed at L'Institut Pierre-Simon Laplace (IPSL), and this version is the atmospheric component of the IPSLCM5A coupled model (Hourdin et al. 2013) used in phase 5 of the Coupled Model Intercomparison Project (CMIP5). The LMDZ is coupled to the latest version of the land surface model ORCHIDEE (Krinner et al. 2005). The configuration used here has a spatial resolution of $2.5^{\circ}$ and $1.25^{\circ}$ in longitude and latitude, respectively, and 39 vertical levels.

First, a set of 19 members starting from a long-term simulation have been run for the period 1854-2000 with the same boundary conditions but different initial state 
of the atmosphere. The boundary conditions imposed on the model to perform these simulations are the sea ice cover, the SST, and the atmospheric gases that affect the external climate forcing. The sea ice cover data used are from HadISST1 (Rayner et al. 2003), extending back to the year 1854 from the monthly climatological data provided for the period 1870-1900. The evolution of the greenhouse gases concentration is the same as used in the historical simulations of CMIP5 (Dufresne et al. 2013). This has been combined with stratospheric aerosol effects estimated from registers of volcanic eruptions (Sato et al. 1993). The ERSST.v4 dataset (Huang et al. 2015; Liu et al. 2015) has been used for the SST forcing, which provides data from 1854 . This latest version has improved metadata bias correction and completeness with respect to previous versions and has been shown to exhibit more realistic SST variability than ERSST.v3 (Huang et al. 2015; Liu et al. 2015; Diamond and Bennartz 2015; Huang et al. 2016).

Second, two different sensitivity experiments have been performed by varying the SST boundary conditions for the period 1854-1910. The initial ensemble of long-term simulations has been used to show that five realizations are a good compromise to extract a significant signal from the internal weather noise on the ensemble mean (details in section 3a). Therefore, the sensitivity experiments are performed with this ensemble size. In one of them [Atlantic sector SST variability (ATLVAR)], the boundary condition imposed in the Atlantic sector is the observed evolution of SSTs, as in the previous long-term simulation of reference (REF). Outside this area, the climatological annual cycle of SSTs relative to 1854-1910 is used. Outputs of this experiment are noted with an "atl" subscript. In the other sensitivity experiment [Indo-Pacific sector SST variability (INPVAR)], the observed SSTs evolution is imposed in the Indo-Pacific Ocean surface, while the Atlantic SSTs are fixed to the climatological annual cycle. Outputs of this experiment are noted with an "inp" subscript. The Atlantic sector spans its entire basin, including the Mediterranean Sea and part of the Arctic and Southern Oceans to the north and south, respectively. Two meridional boundaries at $70^{\circ} \mathrm{W}$ and $12^{\circ} \mathrm{E}$, south of the South American and African continents, separate the Atlantic sector from the Pacific and the Indian Ocean, respectively (see boundaries in Fig. 5b). In these oceanic boundaries, the SST anomalies (SSTA) added to the climatology in one region or another are buffered through a linear relaxation along five grid points.

\section{c. Definition of indices}

A Sahel precipitation index (SPI) is defined as the area-weighted average of the JAS seasonal precipitation across $17.5^{\circ} \mathrm{W}-10^{\circ} \mathrm{E}$ and $10^{\circ}-17.5^{\circ} \mathrm{N}$. Following GA15, the Sahel monsoon season is also described through the ASWI, which corresponds to the proportion of days per month with predominant southwesterly wind across $29^{\circ}-17^{\circ} \mathrm{W}$ and $7^{\circ}-13^{\circ} \mathrm{N}$ and averaged in JAS. The wind direction is obtained from the daily output of the model simulations of wind at $10 \mathrm{~m}$ above the surface. To represent the low- or the high-frequency variability of these indices, a low- or high-pass Butterworth filter, respectively, with an 8-yr cutoff period is applied to the unfiltered time series (representing the total variability). The variability is quantified in terms of the standard deviation.

The time evolution of the low-frequency (LF) variability of the Atlantic SST is characterized by the index of the Atlantic multidecadal oscillation (AMO; Kerr 2000). The AMO index is computed as the first principal component of an empirical orthogonal function analysis of the 13-yr low-pass-filtered residual SSTA of the North Atlantic $\left(0^{\circ}-60^{\circ} \mathrm{N}\right)$, where the residual SSTA stands for a field in which the global warming signal is removed, following Mohino et al. (2011a).

\section{d. Multilinear regression analysis}

To evaluate how much of the total SPI variance of the REF experiment $\left[\operatorname{Var}\left(\mathrm{SPI}_{\mathrm{ref}}\right)\right]$ can be explained by the indices of the two sensitivity experiments $\left(\mathrm{SPI}_{\mathrm{atl}}\right.$ and

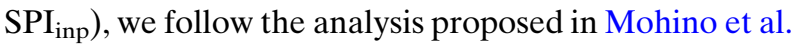
(2016). This is based on the multilinear regression analysis of the former index as the dependent variable with the other two as the independent ones. Then the total variance can be decomposed into four components as follows:

$$
\begin{aligned}
\operatorname{Var}\left(\mathrm{SPI}_{\mathrm{ref}}\right)= & \alpha^{2}+\beta^{2}+2 \alpha \beta \operatorname{Cov}\left(\mathrm{SPI}_{\mathrm{atl}}, \mathrm{SPI}_{\mathrm{inp}}\right) \\
& +\operatorname{Var}(\varepsilon),
\end{aligned}
$$

where $\alpha$ and $\beta$ stand for the multilinear regression coefficients and $\varepsilon$ for the residual of the fit, and $\operatorname{Cov}\left(\mathrm{SPI}_{\mathrm{atl}}\right.$, SPI $\mathrm{I}_{\text {inp }}$ ) is the covariance between both independent variables.

\section{e. Statistical significance of the results}

The statistical significance of the correlation coefficients is evaluated according to the random-phase test of Ebisuzaki (1997), which takes the serial correlation of the time series into account. In cases where a correlation is significant at a confidence level greater than $99 \%$, we refer to it as highly significant.

The Student's $t$ test is also used to evaluate the $95 \%$ statistical significance in spatial patterns comparing two means or mean anomalies with respect to zero and to test the slope of a regression line. 

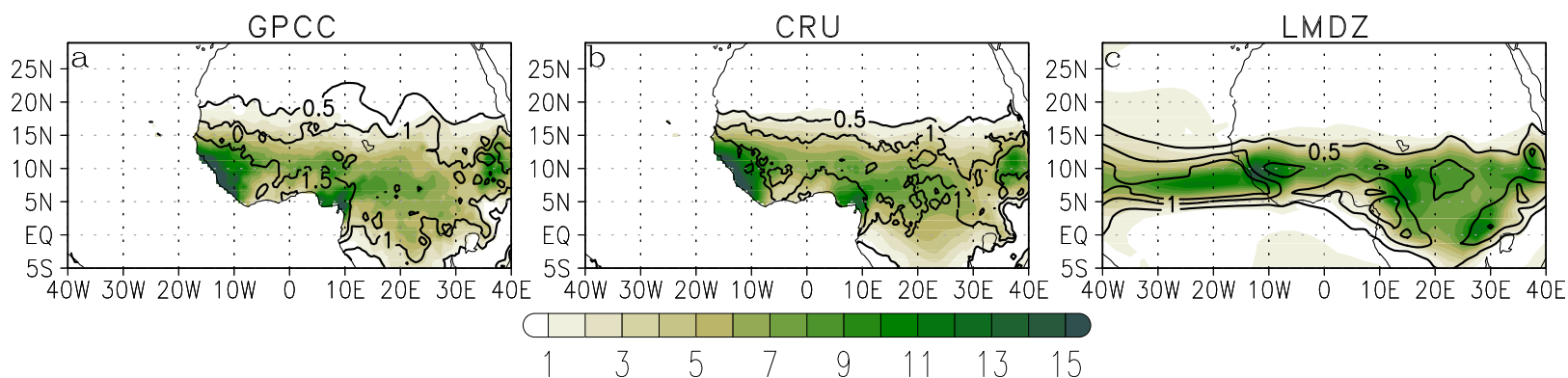

FIG. 1. Climatology (colors) and standard deviation (contours) over 1901-2000 of the JAS precipitation (mm day ${ }^{-1}$ ) for the (a) GPCC and (b) CRU observational datasets and for (c) the ensemble mean of the LMDZ simulations.

\section{Results}

\section{a. Model validation}

\section{1) Climatology}

The climatological Sahel precipitation during JAS simulated by the REF ensemble mean is compared with respect to observations over the 1901-2000 common period (Fig. 1) so as to evaluate the LMDZ's ability to reproduce the main West African rainfall features that affect the Sahel. Over land, the model successfully reproduces a maximum value of the climatological rainfall during JAS toward the north of West Africa: around $10 \mathrm{~mm} \mathrm{day}^{-1}$ is simulated as averaged between $17.4^{\circ} \mathrm{W}$ and $10^{\circ} \mathrm{E}$, which is similar to observations. However, while in observations this maximum reaches latitudes between $10^{\circ}$ and $12^{\circ} \mathrm{N}$, it remains at lower latitudes in the simulations, slightly south of $10^{\circ} \mathrm{N}$. As a consequence, the reproduced climatological JAS precipitation amount over the Sahel (averaged across $17.4^{\circ} \mathrm{W}-10^{\circ} \mathrm{E}$ and $10^{\circ}-17.5^{\circ} \mathrm{N}$ ) is underestimated by $23 \%$ with respect to observations (from the GPCC and CRU datasets).

\section{2) VARIABILITY}

The total variance of the ensemble-mean rainfall in West Africa simulated by the model is also underestimated with respect to observations (Fig. 1), reproducing $65 \%$ of the observed standard deviation over the Sahel at decadal time scales (Table 1). Part of the underestimation of the observed Sahel rainfall low-frequency variability comes from the averaging among all members, which accounts for an underestimation of $7 \%$ of the standard deviation of the individual simulations (Table 1). Nevertheless, the standard deviation of the low-frequency SPI reproduced by the individual simulations is reduced by $31 \%$ of the observed one, on average. At all time scales, the SPI standard deviation is similarly underestimated. This indicates that the observed Sahel rainfall variability is underestimated by roughly onethird by the LMDZ in response to the forcings imposed. Other studies have also shown that, in general, AGCMs have a weak response of West African rainfall to the SST forcing (e.g., Joly et al. 2007; Rodríguez-Fonseca et al. 2011; Kucharski et al. 2013; Vellinga et al.2016). This is typically attributed to the coarseness of the AGCM's spatial resolution and to the accuracy with which land-atmosphere feedbacks are parameterized (Giannini et al. 2003; Cook and Vizy 2006; Vizy et al. 2013; Vellinga et al. 2016).

\section{3) Mechanism}

To validate the way the LMDZ simulates decadal shifts of the WAM, we concentrate on the Sahel drought of the twentieth century: the difference between the simulated mid-twentieth-century rainy period (averaged from 1948 to 1963) and the subsequent dry one (196998 ) is compared to observations. Observational data of precipitation reveal a contrast of abundant rainfall throughout the Sahel and a shortage to the south during the rainy period with respect to the dry one (Fig. 2a), which is accurately reproduced by the LMDZ (Fig. 2b). Nevertheless, consistent with the reproduced climatology (Fig. 1), the LMDZ underestimates the observed amounts of rainfall in the north of the Sahel region and, outside of West Africa, it is not very realistic east of $25^{\circ} \mathrm{E}$.

The difference between the rainy period and the dry one in the vertical profiles of the specific humidity and moisture flux over West Africa, averaged between $10^{\circ} \mathrm{W}$

TABLE 1. Standard deviation of the unfiltered (TOT) and the LF SPI (mm day ${ }^{-1}$ ) from the GPCC and CRU observations, from the simulations considering the 19 members individually and then averaged ( $\left.\mathrm{LMDZ}_{\text {indiv }}\right)$, and from the ensemble-mean SPI (LMDZ $\left.\mathrm{L}_{\text {ens-mean }}\right)$.

\begin{tabular}{lcccc}
\hline \hline & GPCC & CRU & LMDZ $_{\text {indiv }}$ & LMDZ $_{\text {ens-mean }}$ \\
\hline TOT & 0.766 & 0.752 & 0.492 & 0.419 \\
LF & 0.535 & 0.566 & 0.380 & 0.355 \\
\hline
\end{tabular}




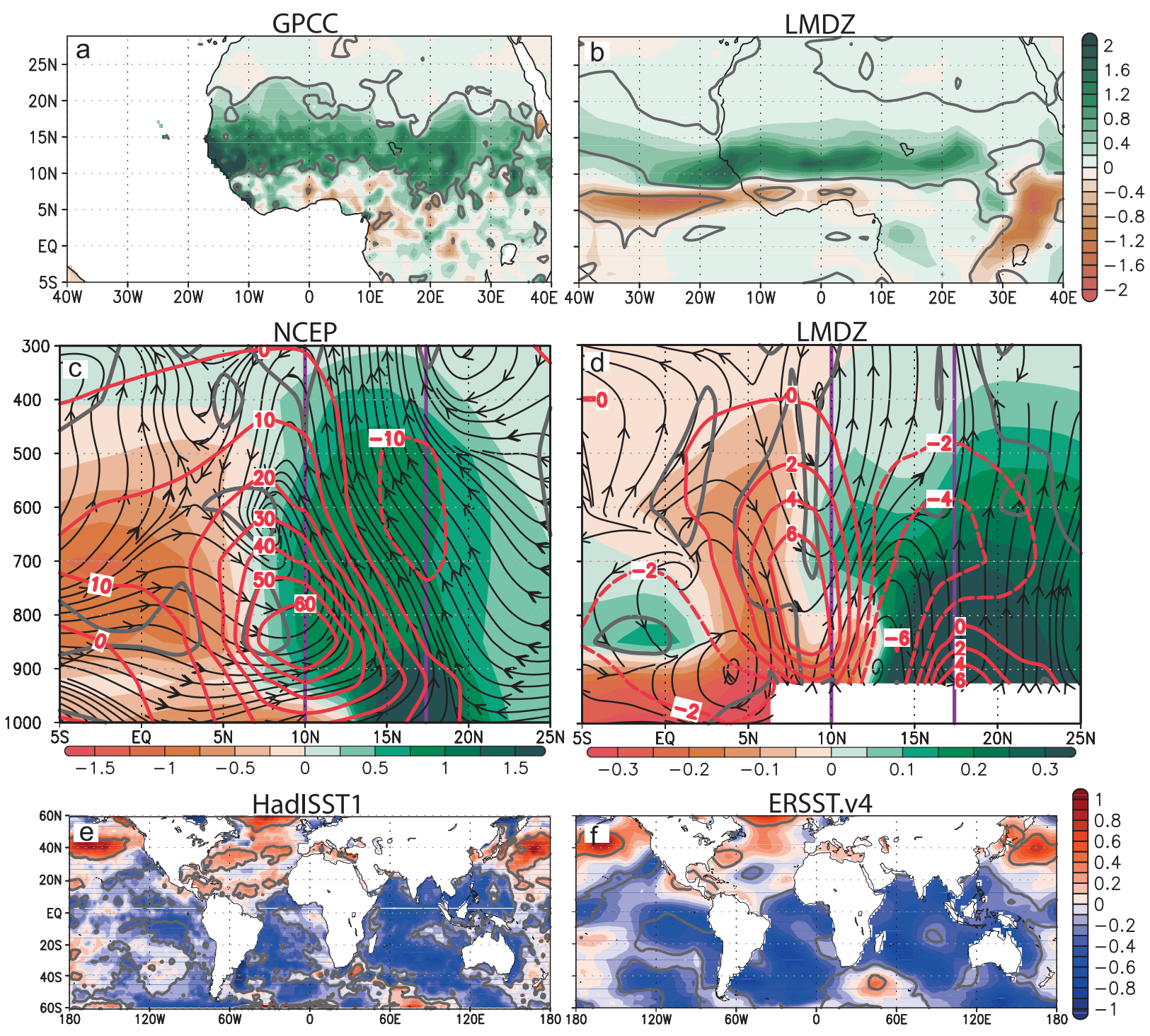

FIG. 2. Difference between the 1948-63 and the 1969-98 mean of JAS precipitation in (a) observations and (b) the ensemble-mean LMDZ simulations. Homologous pattern of the JAS vertical profile, averaged between $10^{\circ} \mathrm{W}$ and $10^{\circ} \mathrm{E}$, of the specific humidity $\left(\mathrm{g} \mathrm{kg}^{-1}\right.$; color shading), the zonal moisture flux $\left(\mathrm{g} \mathrm{kg}^{-1} \mathrm{~m} \mathrm{~s}^{-1}\right.$; red contours), and its vertical and latitudinal components (unrealistic units; black streamlines) in (c) the NCEP reanalysis and (d) the ensemble-mean LMDZ simulations. Same time period difference of the JAS SST from (e) HadISST1 and (f) ERSST.v4 datasets. Gray contours indicate where the magnitude of precipitation in (a) and (b), the streamlines in (c) and (d) or SST in (e) and (f) averaged over both periods is significantly different between each other at the 5\% confidence level following a $t$ test for the comparison of two means. Purple lines in (c) and (d) indicate the latitudinal limits of the Sahel.

and $10^{\circ} \mathrm{E}$, obtained for the NCEP reanalysis and the LMDZ simulation, is shown in Figs. $2 c$ and $2 d$, respectively. In agreement with the reanalysis, the LMDZ simulates a shift toward the north of the deep convection related to the intertropical convergence zone (ITCZ), the midlevel easterly flow (associated with the African easterly jet; Cook 1999; Grist and Nicholson 2001), and the humidity distribution in the troposphere during the wet period relative to the dry one. Such a decadal shift of the Sahel rainfall and the described mechanism are associated with an interhemispheric pattern of the Atlantic SST (Figs. 2e,f; Folland et al. 1986; Zhang and Delworth 2006; Knight et al. 2006; Ting et al. 2011; Martin and Thorncroft 2014; Martin et al. 2014). Hence, it is shown that the LMDZ broadly reproduces the main atmospheric mechanisms leading the decadal Sahel rainfall variations observed in the twentieth century in response to the SST. Nevertheless, the model underestimates the zonal moisture flux, consistent with underestimated wind intensity (not shown), the moisture 


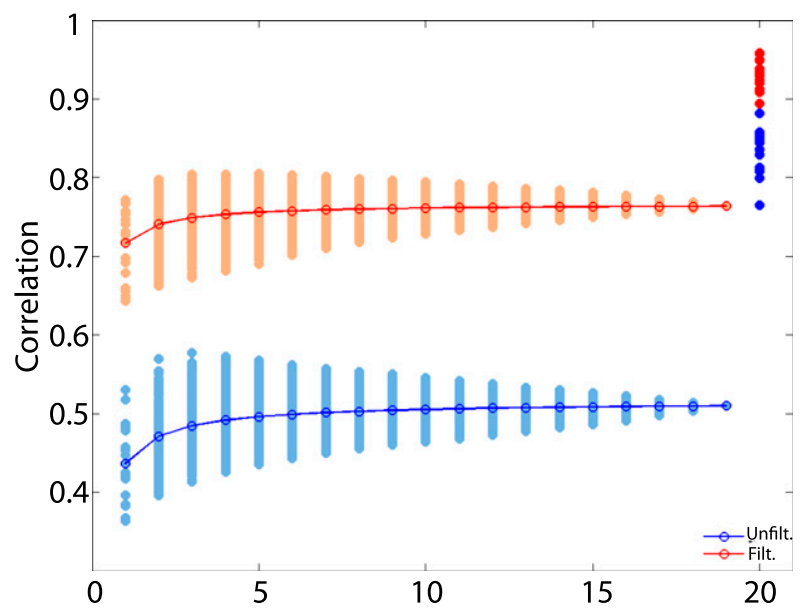

FIG. 3. Correlation coefficients between the 8-yr low-passfiltered (orange dots) and unfiltered (light blue dots) SPI of the GPCC dataset and the ensemble mean over all possible combinations from 1 to 19 reproduced members in the LMDZ simulations. The horizontal axis indicates the number of members averaged. The open circles indicate the mean values among all the correlation coefficients obtained for each ensemble. The dark dots at the upper right denote the correlation coefficients between the 8-yr low-passfiltered (red) and unfiltered (blue) SPI of each individual member and the ensemble mean of the remaining 18 .

convergence over the Sahel, and the tropospheric content of humidity (note the different contour and color shade scales used in Figs. 2c,d). This is consistent with the underestimation of the observed precipitation variability and climatology (Fig. 1). Locally, there are slight discrepancies between the simulations and the reanalysis, such as the low-level vertical anomalous flow around $14^{\circ}-$ $18^{\circ} \mathrm{N}$. A possible explanation for these discrepancies could be the intensity of local SST gradients represented by the observational datasets in certain regions affecting the WAM variability, such as the subtropical North Atlantic, the Mediterranean Sea, and the Indian Ocean (Giannini et al. 2013; Martin et al. 2014). It is expected that the inherent uncertainties of the SST data used will have an effect on the simulations. Notwithstanding, the described discrepancies between simulations and the reanalysis do not affect the way the LMDZ reproduces the main characteristics of the West African precipitation climatology and its variability during the rainy season.

\section{4) ENSEMBLE SIZE}

So as to evaluate the robustness of the results obtained with respect to the uncertainty coming from weather noise, the correlation between the observed SPI (from GPCC data between 1901 and 2000) and the ensemble-mean index using from 1 to 19 members in all the possible combinations is shown in Fig. 3, following Caminade and Terray (2010). The mean of the correlation coefficients of the unfiltered indices rapidly converges to around $R=0.50$. Regarding the 8 -yr lowpass-filtered indices, the mean value of the correlation coefficients also quickly converges to $R=0.75$. This means that the simulated Sahel precipitation can explain around $30 \%$ and $60 \%$ of the observed shifts of the Sahel rainfall at all and at decadal time scales, respectively. The rapid convergence of the correlation mean coefficients to a stable value suggest that the correlation with observations will not increase significantly by adding more members. It also suggests that fewer than 19 members can be used to obtain a robust estimation of the simulated response. For the sensitivity experiments ATLVAR and INPVAR, we chose five members as a compromise between computational effort and robustness of the results. The correlation between the SPI of each one of the 19 members separately with the ensemble mean of the remaining 18 simulations is also shown (filled dark red and blue dots in Fig. 3). Their high values of about 0.85 and 0.95 , respectively, at all time scales and at decadal ones, is also indicative of the strong influence of the external forcing in the Sahel rainfall variability with respect to the random noise of the model.

\section{b. The Sahel rainfall time evolution}

The observed SPI presents good agreement with the ASWI of GA15 (Fig. 4). Both show marked decadal variability, with an anomalously rainy period over 194563 followed by a dry one lasting to the end of the twentieth century, with a partial recovery. Over the late nineteenth century, the ASWI suggests a long-lasting wet period over 1845-90 and more intense than the one of the twentieth century. In turn, the Sahel index based on the semiquantitative reconstruction of NI12 supports the occurrence of such an early long rainy period but shorter (roughly from 1866 to 1892) and less intense than the one in the twentieth century.

Our simulated SPI describes a similar evolution along the twentieth century to the observed one (Fig. 4). The low-pass-filtered simulated and observed SPI indices are strongly correlated over the twentieth century $(R=0.77$, highly significant). The simulations successfully reproduce the observed low-frequency evolution between peaks of maximum or minimum precipitation in the Sahel. They also reproduce the anomalous humid period of the mid-twentieth century, the subsequent dry one, and the partial recovery at the end of the twentieth century. The main discrepancy is around the year 1940, when the simulations reproduce an intense increase of precipitation in contrast to observations. This inconsistency may be attributed to the high uncertainty of the SST data during the Second World War rather than 


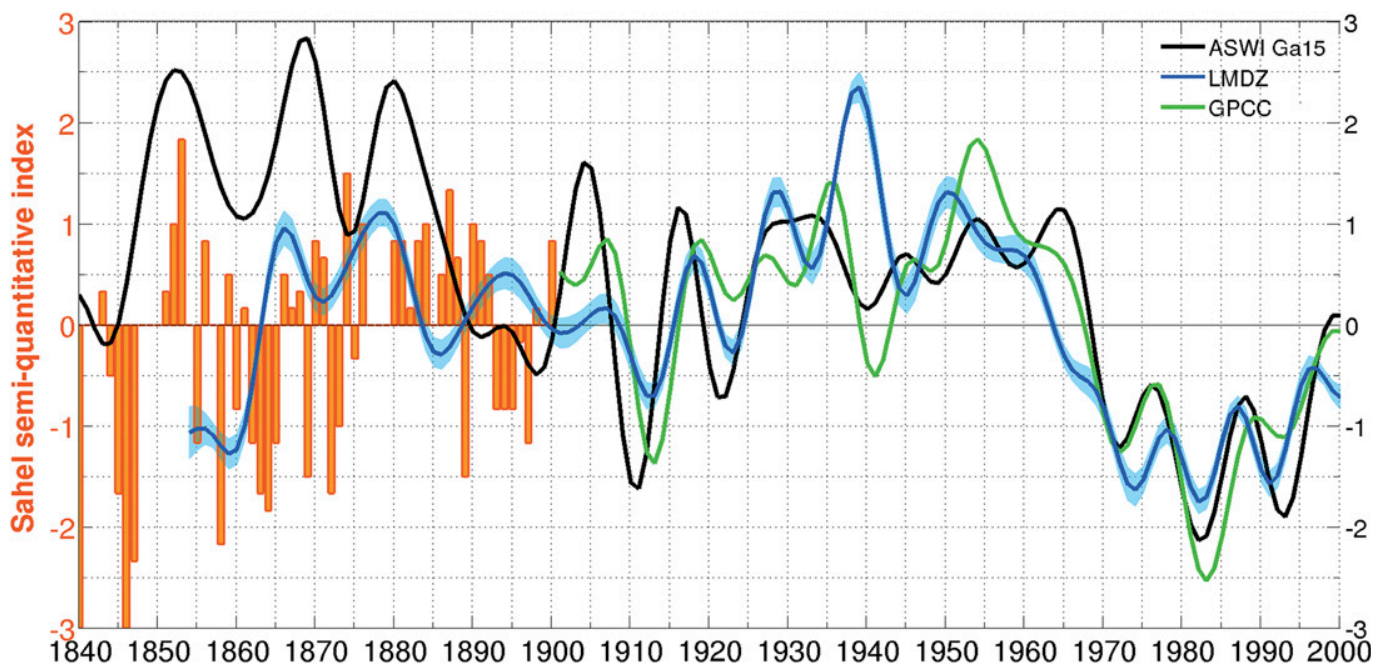

FIG. 4. The bars show the semiquantitative index of Sahel precipitation of the reconstruction of NI12. The lines represent the seasonal ASWI in JAS of GA15 (black) and the observed index of JAS seasonal precipitation in the Sahel (averaged in $17.5^{\circ} \mathrm{W}-10^{\circ} \mathrm{E}, 10^{\circ}-17.5^{\circ} \mathrm{N}$ ) in observations (green) and in the ensemble-mean simulation (blue). The last three indices have been low-pass filtered with an 8-yr cutoff period and standardized with respect to the observed period (1901-2000). The blue shading is the standard deviation among the 19 members simulated.

to the model skills (Thompson et al. 2010; Kennedy 2014; Huang et al. 2016). In addition, the shift from positive to negative anomalies occurs during 1964, five years earlier than in observations and the ASWI of GA15.

At decadal time scales, the reproduced SPI is also positively correlated with the observed ASWI of GA15 in the 1854-2000 period ( $R=0.53$, significant at the $87 \%$ confidence level). Regarding the second half of the nineteenth century, the simulations reproduce an anomalously rainy period from 1863 to 1883 with respect to the twentieth-century climatology. This is consistent with GA15 and NI12. Before 1863, though, the two reconstructions do not agree and the simulations reproduce anomalous drought conditions in the Sahel, in agreement with NI12 but not with GA15. Furthermore, the simulated rainy period ends around 1883 , which is six years earlier than suggested by GA15. As far as intensity and duration are concerned, this late nineteenth-century rainy period is comparable to the mid-twentieth-century (1945-63) one in the simulations. This is in contrast with the result of GA15, which suggests that the Sahel rainfall was exceptionally strong over most of the second half of the nineteenth century.

The simulated spatial pattern of anomalous precipitation over the late nineteenth-century rainy period (1863-83) shows significant positive anomalies over the Sahel (Fig. 5a). South of $10^{\circ} \mathrm{N}$, there is a strong deficit of precipitation in the tropical Atlantic and nonsignificant anomalies inland. This pattern is similar to the one of the contrast between the rainy and dry period of the mid- and the late twentieth century, respectively, that the simulations reproduce (Fig. 2b).

Therefore, these results show that, albeit some differences in terms of timing and intensity, our simulations succeed in reproducing an unprecedented decadal wet period in the late nineteenth century, supporting the evidences of its existence (shown by GA15 and NI12), and which has a similar pattern to that of the mid-twentieth century. Such favorable comparison between simulated and observed Sahel rainfall variability since the nineteenth century suggests that our model experiments can help shed some light on the physical mechanisms at play.

\section{c. Mechanisms involved in the late nineteenth-century wet period}

During the Sahel humid period of the late nineteenth century, the LMDZ simulations show reinforced monsoonal rainfall over West Africa (Fig. 5a). There is a significant abundance of precipitation throughout a zonal band that covers the Sahel region (from the western coast to $10^{\circ} \mathrm{E}$ and between $10^{\circ}$ and $17.5^{\circ} \mathrm{N}$ ), while the surrounding continental areas do not present significant rainfall anomalies. Over the tropical Atlantic, roughly within $3^{\circ}-12^{\circ} \mathrm{N}$, there is a marked deficit of rainfall.

This distribution of precipitation anomalies is associated with SSTA that broadly present an interhemispheric gradient in the Atlantic basin, with mostly warm SSTA in the northern half and cold ones to the south (Fig. 5b). A band of intense cold SSTA extends from the southwestern to northeastern tropical North Atlantic. This cooling, 


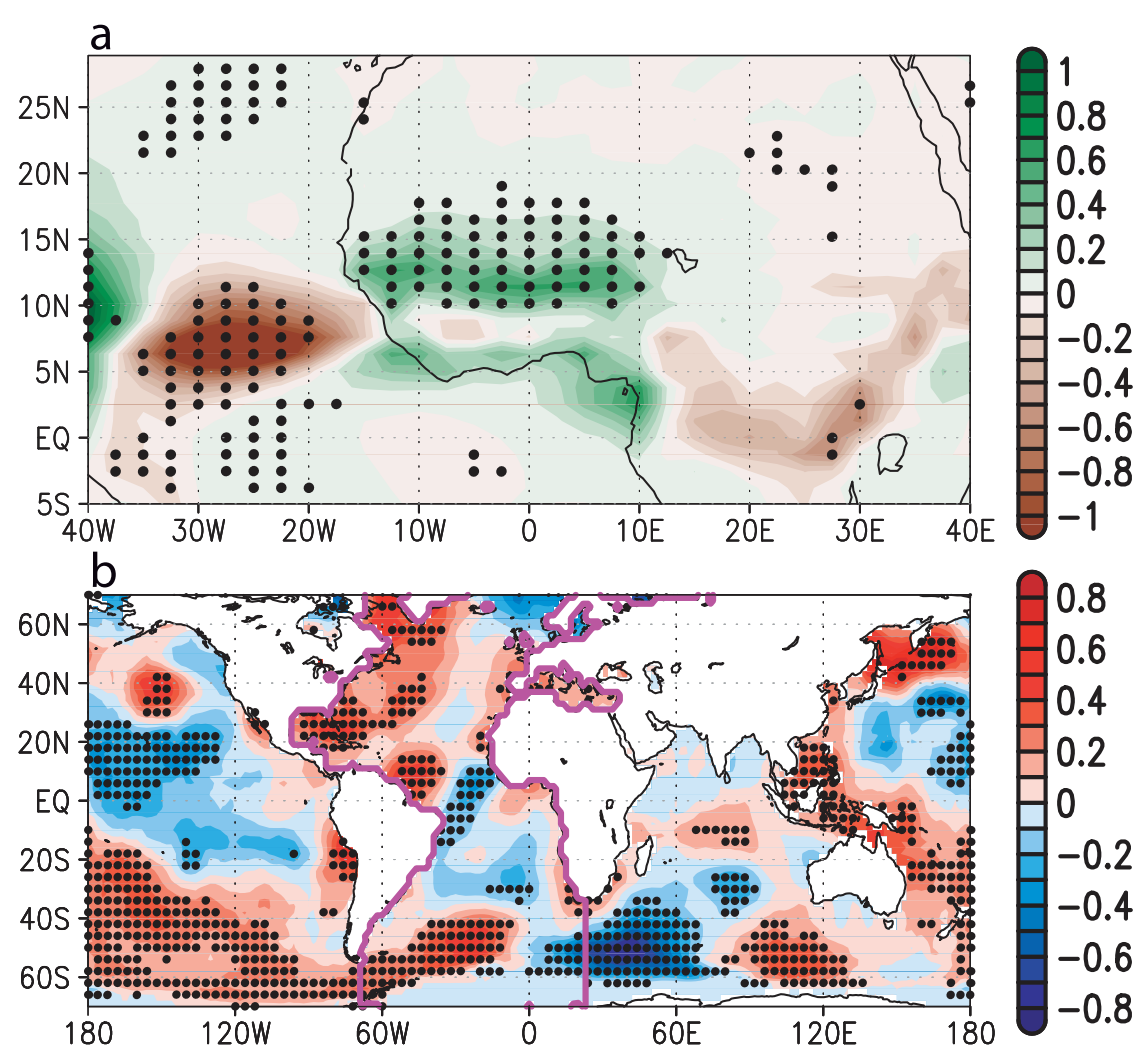

FIG. 5. The 1863-83 mean JAS seasonal anomalies with respect to the 1854-2000 climatology of (a) precipitation $\left(\mathrm{mm} \mathrm{day}^{-1}\right.$ ) of the ensemble-mean LMDZ simulation and (b) SSTA (K) of the ERSST.v4 dataset. Black dots indicate the regions where the averaged anomalies over the period $1863-83$ are significantly different from zero at the 5\% level (from a $t$ test). The purple line indicates the boundary between the regions of the SST field differentiated to perform the sensitivity experiments.

along with the warm coastal SSTA farther north, creates a strong thermal contrast around $10^{\circ} \mathrm{N}$ in the vicinity of West Africa. In more remote basins, there are remarkable negative SSTA in the central Pacific basin and positive ones in the extratropics, the Maritime Continent, and the southern tropical Indian Ocean. This SSTA pattern presents broad similarities with the one associated with the twentieth-century shift of the Sahel rainfall (Figs. 2e,f; i.e., interhemispheric contrast of Atlantic SSTA, central Pacific cooling, and extratropical North Pacific warming), suggesting that the decadal variations of the Sahel precipitation may have occurred under similar SST conditions.

To understand the mechanisms driving the rainfall increase in the Sahel during the late nineteenth century, we analyze the mean simulated atmospheric state over the same period (Fig. 6). In the Pacific, two subtropical cores of high surface pressure indicate anomalous anticyclonic formations reminiscent of the Matsuno-Gill response to the tropical SST cooling (Matsuno 1966; Gill 1980; Fig. 6a). Consistent with this pattern, the positive velocity potential anomalies at the $200-\mathrm{hPa}$ level show anomalous convergence over the tropical Pacific, which favors local subsidence. The negative velocity potential anomalies suggest enhanced high-level divergence and rising vertical motion over the Maritime Continent and Central America. Such a pattern suggests a strengthening of the Walker circulation associated with the anomalous tropical Pacific cooling (Gill 1980). However, this pattern does not significantly reach the region of West Africa. On the other hand, there is a widespread decrease of surface pressure over the warm North Atlantic. These anomalies create an oblique pressure gradient, from the negative ones in the northwest to the positive ones in the southeast tropical North Atlantic, which is statistically significant and consistent with the SSTA pattern. Associated with this, there is anomalous upward vertical wind at the $500-\mathrm{hPa}$ level right over the Sahel region and downward to the south, being most significant over the tropical Atlantic (Fig. 6b). This indicates an anomalous northward shift of the ITCZ coherent with the rainfall increase in the Sahel (Rowell et al. 

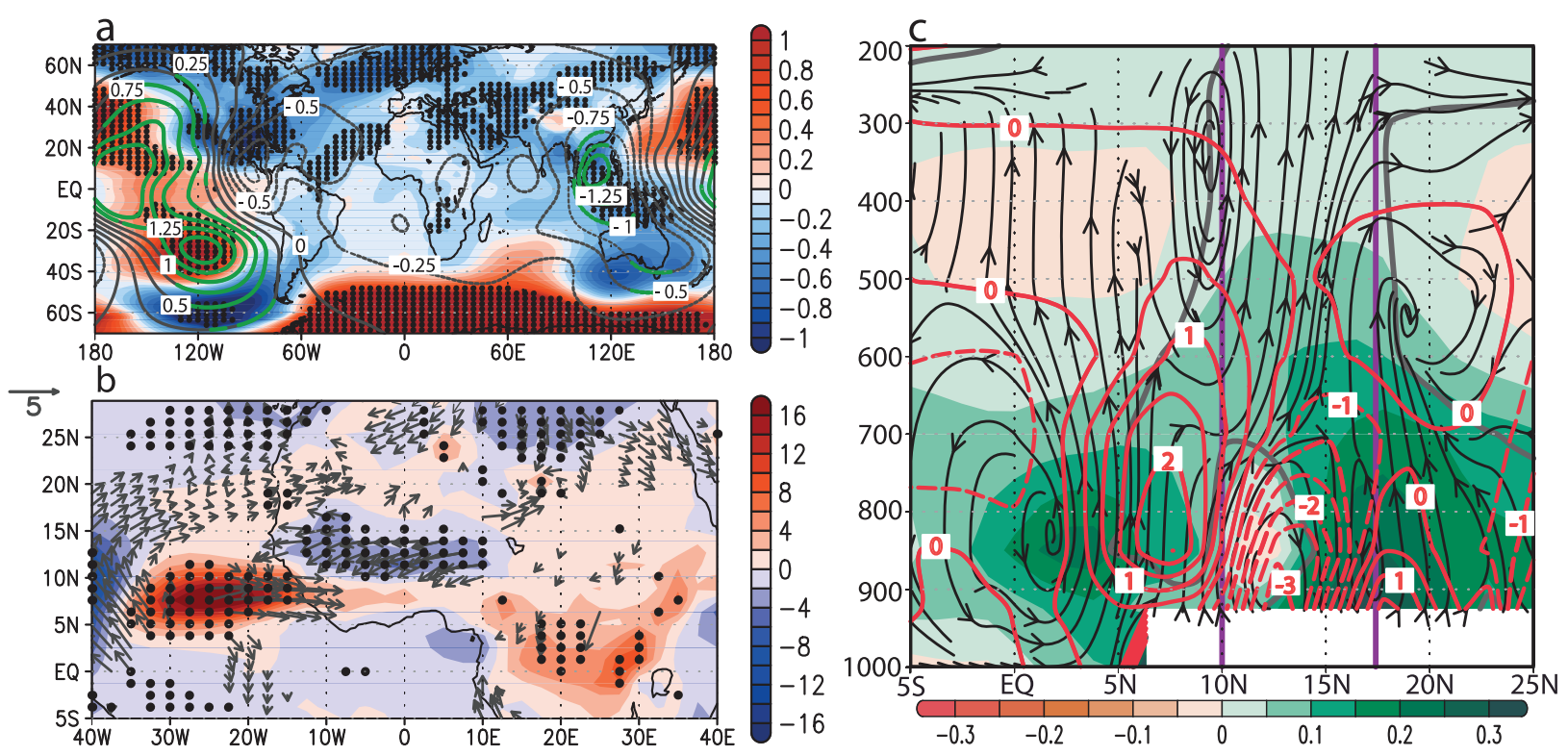

FIG. 6. The 1863-83 mean JAS seasonal anomalies with respect to the entire simulated period (1854-2000) of different variables. (a) The surface pressure (hPa; color shading; black dots indicate statistical significance) and the velocity potential at the $200-\mathrm{hPa}$ level $\left(10^{6} \mathrm{~m}^{2} \mathrm{~s}^{-1}\right.$; contours; green contours where it is significant). (b) The omega vertical velocity at the $500-\mathrm{hPa}$ level $\left(10^{-3} \mathrm{~Pa} \mathrm{~m}^{-1}\right.$; $\mathrm{color}$ shading; black dots indicate significance) and the horizontal moisture flux at $925 \mathrm{hPa}\left(\mathrm{g} \mathrm{kg}^{-1} \mathrm{~m} \mathrm{~s}^{-1}\right.$; vectors; plotted where the anomalies of any of the two wind components are significant). (c) The vertical profile (averaged between $10^{\circ} \mathrm{W}$ and $10^{\circ} \mathrm{E}$ ) of the specific humidity ( $\mathrm{g} \mathrm{kg}^{-1}$; colors; gray contours indicate significance), the zonal moisture flux $\left(\mathrm{g} \mathrm{kg}^{-1} \mathrm{~m} \mathrm{~s}^{-1}\right.$; red contours), and its vertical and latitudinal components (unrealistic units; black streamlines). The significance of all the anomalies is calculated for a $5 \%$ level following a $t$ test applied to the average over the period 1863-83. Purple lines in (c) indicate the latitudinal limits of the Sahel. All variables are obtained from the ensemble mean of all the simulations.

1992; Knight et al. 2006). Near the surface (at the 925-hPa level), there is an anomalous westerly moisture flux from the tropical Atlantic inland between $5^{\circ}$ and $10^{\circ} \mathrm{N}$ and northeasterly over the Sahel land surface. These moisture flux anomalies are primarily due to anomalous horizontal winds ( $\mathrm{Pu}$ and Cook 2010) rather than to changes in the air humidity content (not shown).

The near-surface cross-equatorial monsoon flow presents a strengthening as well as convergence slightly south of $10^{\circ} \mathrm{N}$, as shown in the vertical profile (Fig. 6c). In turn, the vertical moisture transport at medium and low levels is reinforced south of the Sahel, with a maximum of anomalous humidity around $850 \mathrm{hPa}$. The anomalous winds carry part of this humidity upward to midlevels $(700-500 \mathrm{hPa})$ and toward the north, over the Sahel. The weakening of the midlevel climatological easterly winds, associated with the African easterly jet, is also consistent with the midtroposphere moistening above the Sahel (Cook 1999). To the north, there is lowlevel moisture transport associated with wind anomalies from the Atlantic between $15^{\circ}$ and $20^{\circ} \mathrm{N}$ that penetrates north of the Sahel. Such anomalous moisture inflow, together with a weaker one coming from the Mediterranean Sea, results in a large accumulation of low-level humidity in the northernmost Sahel. The humid air, in turn, rises, contributing to moistening even more the midlevel air over the Sahel. The air rise is favored by the strengthening of the intertropical discontinuity at around $18^{\circ} \mathrm{N}$, which climatologically produces dry convection at the boundary between the Sahel and the Sahara Desert (Hall and Peyrillé 2006). As a result of the surface moisture inflow from the south and the north, there is anomalous moisture convergence in the air column over the Sahel, which is associated with enhanced precipitation (Pomposi et al. 2015). Above $600 \mathrm{hPa}$, there is an intensification of rising air between $10^{\circ}$ and $20^{\circ} \mathrm{N}$ and a weakening between $5^{\circ}$ and $10^{\circ} \mathrm{N}$. This means stronger deep convection over the Sahel associated with the already noted anomalous northward shift of the ITCZ. The anomalous deep convection favors the aforementioned convergence of shallow moisture to midlevels above the Sahel, which, in turn, may contribute to further intensify deep convection. Therefore, the combination of the anomalously abundant humidity supply and enhanced deep convection explains the Sahel rainfall enhancement. However, the anomalous northeasterly low-level moisture flux over the Sahel, likely associated with the aforementioned anomalous convergence slightly south of $10^{\circ} \mathrm{N}$, shows a humid flow out of the region, suggesting a drying of the air in the 


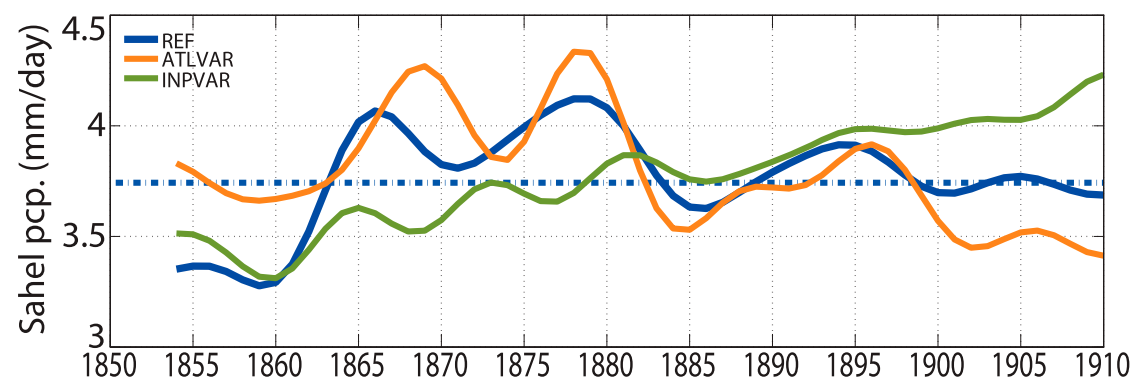

FIG. 7. The 8-yr low-pass-filtered SPI ( $\mathrm{mm} \mathrm{day}^{-1}$ ) of the ensemble-mean REF simulation (dark blue) and the ATLVAR (orange) and INPVAR (green) sensitivity experiments. The hatched blue line indicates the 1854-2000 climatological value of the REF simulation SPI.

southern half where, on the other hand, it rains more. Summarizing, the reproduced late nineteenth-century period of abundant Sahel precipitation is associated with an anomalous enhanced humidity supply and deep convection in the mid- and high troposphere related to wind anomalies, which could be induced by the Atlantic SSTA.

This mechanism is comparable to the one inducing the major decadal shift of the Sahel rainfall from the mid- to late twentieth century (Fig. 2d). In both cases, the Sahel rainfall anomalies are associated with a shift of the ITCZ and anomalous low-level westerly moisture transport between $15^{\circ}$ and $20^{\circ} \mathrm{N}$. However, there are some differences, in particular regarding the moisture distribution over West Africa. Associated with the twentiethcentury rainfall shift, the moisture transport contrast between the Sahel and the Gulf of Guinea is more pronounced than during the late nineteenth-century rainy period, probably related to the stronger and better defined interhemispheric gradient of SSTA in the tropical Atlantic (Figs. 2f, 5b). Nevertheless, despite this difference, the amounts of the simulated Sahel rainfall averaged over the late nineteenth century (1863-83) and the mid-twentieth century (1945-63) are similar (0.26 $\mathrm{mm} \mathrm{day}^{-1}$ above the climatology over 1854-2000). Therefore, this result suggests that the late nineteenthcentury rainy period was produced in a similar way to the mid-twentieth-century one.

\section{d. The role of the Atlantic and Indo-Pacific}

To evaluate the role of the Atlantic and Indo-Pacific Oceans in driving the unprecedented Sahel rainy period of the late nineteenth century, we analyze the two additional SST-sensitivity experiments for the period 1854-1910, in which all the SST variability is left, respectively, in the Atlantic (ATLVAR) or Indo-Pacific (INPVAR) basins, while the remaining global oceanic surface is fixed to the monthly climatology relative to 1854-1910. The other boundary conditions remain unchanged with respect to the previous REF simulations.
Figure 7 highlights the role of the Atlantic SST in driving the decadal Sahel precipitation variability along 1854-1910. The low-frequency SPI of the ATLVAR experiment shows a late nineteenth-century rainy period, in 1863-83, that is similar to the one of the REF simulations, even with higher peak values. While, in contrast, the INPVAR experiment simulates less precipitation. After 1883, ATLVAR and INPVAR experiments, respectively, reproduce less and more Sahel precipitation than the REF simulations.

Regarding the state of the atmosphere averaged over 1863-83, the ATLVAR experiment shows lower surface pressure over the North Atlantic than the REF simulations (Fig. 8a), which is associated with a wider ITCZ shift that favors the Sahel rainfall (Knight et al. 2006; Martin and Thorncroft 2014). In addition, over the Indian Ocean, the surface pressure is higher in ATLVAR than in REF. Consistently, there is more high-level convergence locally and more high-level divergence over West Africa in the former than in the latter, consistent with more Sahel rainfall in ATLVAR than in REF. On the other hand, the resulting surface pressure from the INPVAR experiment is high with respect to REF simulations all over the Atlantic basin and the surrounding continents, particularly over West Africa, coinciding with high-level convergence (Fig. 8b). The surface pressure is lower than in REF in the rest of the globe, and there is more high-level divergence over the central Pacific and the northern Indian Ocean.

Therefore, these results suggest that the SST variability of the Atlantic and Indo-Pacific basins have contrary effects on the Sahel rainfall in the 1854-1910 period: whereas the Atlantic seems to drive changes in the Sahel rainfall regime, shifting from dry to rainy in 1863 and back to dry in 1883, the role of the Indo-Pacific SST is rather to attenuate these effects through local subsidence anomalies.

A multilinear regression analysis (see details in section 2d) reveals that the low-frequency SPI of the ATLVAR experiment accounts for most (76\%) of the 


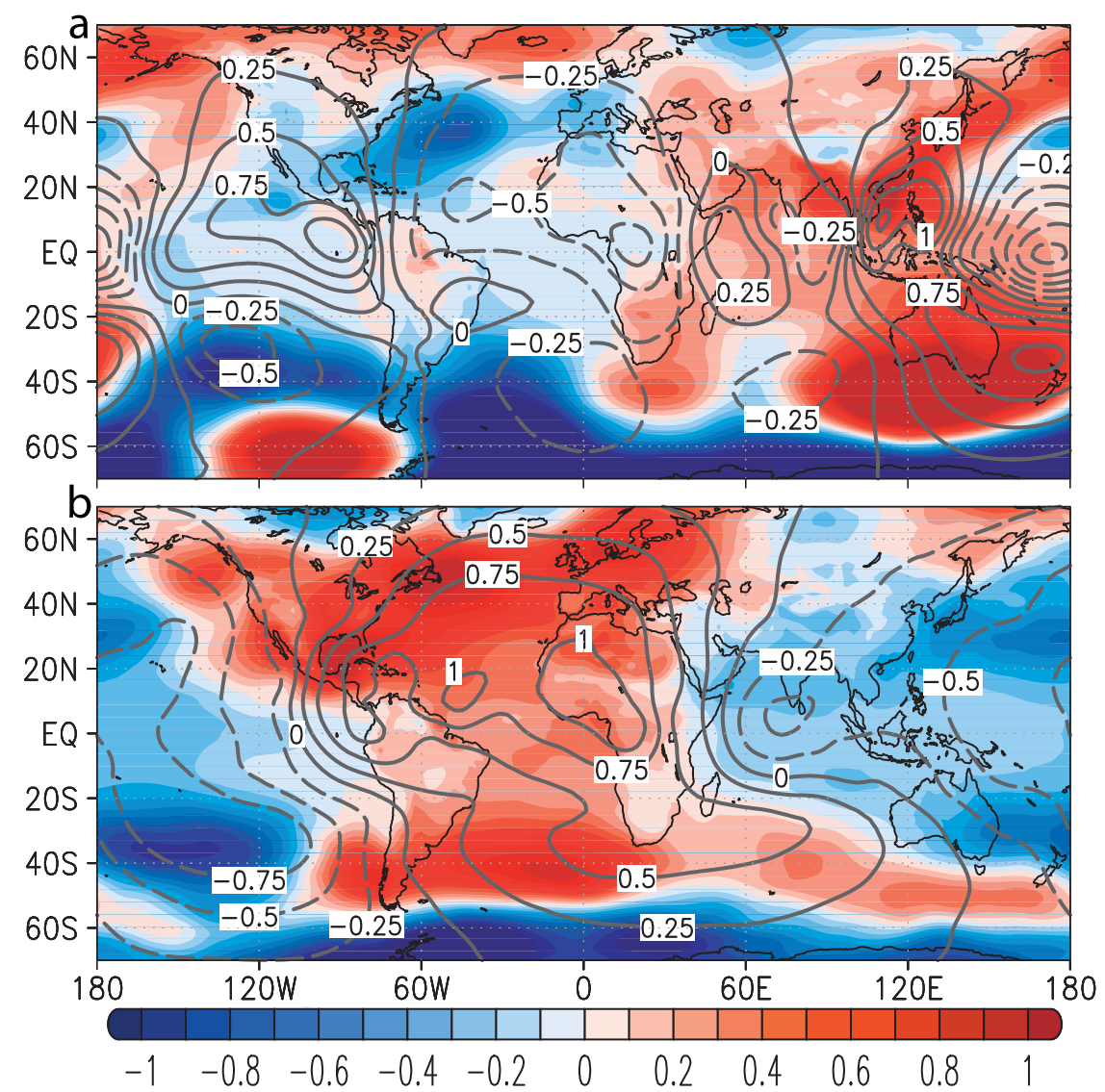

FIG. 8. Difference of the 1863-83 mean JAS surface pressure (hPa; color shading) and the velocity potential at the $200-\mathrm{hPa}$ level $\left(10^{6} \mathrm{~m}^{2} \mathrm{~s}^{-1}\right.$; contours) resulting from the (a) ATLVAR and (b) INPVAR experiments minus the REF simulations. The variables are obtained from the ensemble mean of all the simulations.

SPI variance of the REF simulations (Fig. 9a). This result evidences that the Atlantic SST variability itself is responsible for the vast majority of the reproduced decadal changes in the Sahel precipitation over the period 1854-1910. In addition, the compensation between the variance explained by the INPVAR and the covariance term suggests that the variability of the Atlantic and Indo-Pacific SST is not completely decoupled.

In contrast, at interannual time scales, these two components are notably decoupled (Fig. 9b). In this case, the multilinear regression model shows that the low-frequency SPI of the INPVAR experiment is the component that accounts for more of the SPI variance reproduced by REF (40\%). This is consistent with the important link between the interannual tropical Pacific SST variability and the Sahel rainfall (Janicot et al. 1996, 1998, 2001; Mohino et al. 2011b). Instead, the Atlantic SST influence on the low-frequency SPI variability plays a secondary role.

To find out how representative the ASWI is of the Sahel rainfall variability in relation to the SST, a similar multilinear regression analysis is applied to the simulated ASWI. The result suggests that the simulated ASWI responds almost exclusively to the Atlantic SST variability at all time scales (Figs. 9c,d). Furthermore, the low-frequency ASWI (Fig. 10) and SPI simulated by REF are strongly correlated $(R=0.89$, highly significant) along the entire simulated period. Such a tight relationship at a decadal time scale between both indices is in agreement with observations. Therefore, the ASWI can be considered as a good indicator of the Sahel rainfall variability (as hypothesized by GA15) as long as the rainfall is modulated by the Atlantic SST, which occurred at decadal time scales in the late nineteenth century.

\section{Discussion}

\section{a. Long-term linear trend of the ASWI}

At a longer-than-decadal time scale, the ASWI of GA15 presents a marked negative trend along the 1854-2000 period (Fig. 10), which suggests a centennial 

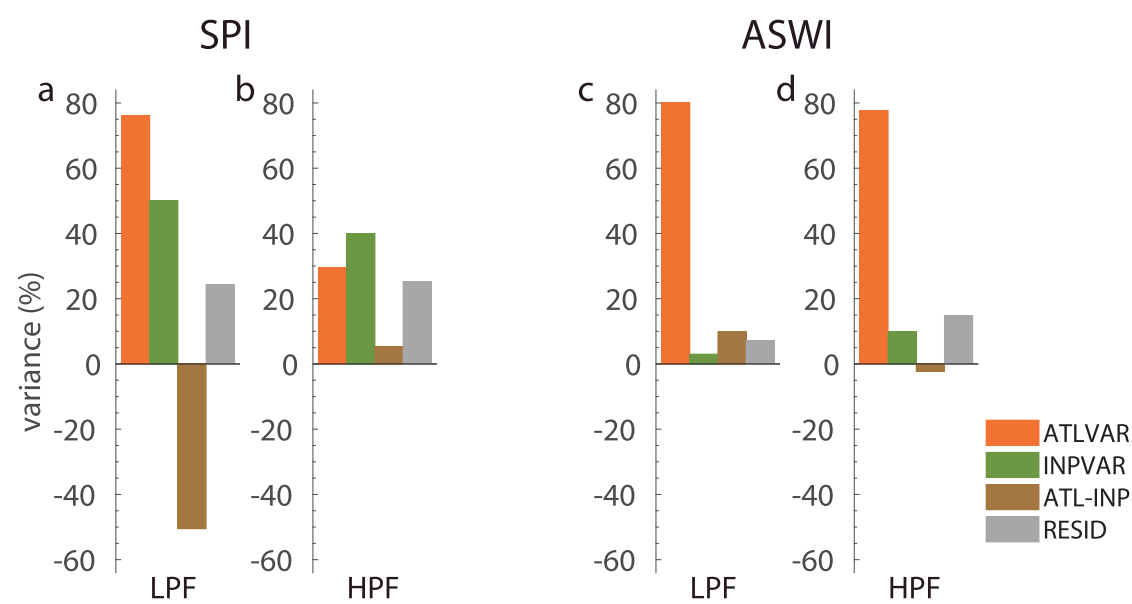

FIG. 9. Bar charts of the components (\%) of the SPI total variance reproduced by REF at (a) decadal (8-yr low-pass filtered) and (b) interannual time scales (8-yr high-pass filtered) explained by the two indices of the sensitivity experiments using a multilinear regression analysis. (c), (d) As in (a) and (b), respectively, but for the ASWI. The components correspond to the indices of ATLVAR (orange), INPVAR (green), the covariance between both (brown), and the residual of the multilinear regression fitting (gray).

drying trend of the Sahel. The ASWI from the LMDZ simulations reproduces a negative linear trend as well. Nevertheless, both indices disagree on the slope of such a linear trend: 12.4 ASWI units (\%) per century (highly significant) for the ASWI of GA15 and 1.6 ASWI units (\%) per century (not significant) for the LMDZ simulation. Such disagreement may be due to an underestimation of the drying trend by the model. This underestimation could be related to the model sensitivity to the competing effects of global SST warming and carbon dioxide concentration increase, which dampen and favor the Sahel rainfall, respectively (Gaetani et al. 2017). On the other hand, the results from NI12 (their Fig. 10a) also disagree with GA15 on the strength of the nineteenth-century wet period, suggesting that the results from the latter could be overestimating the negative trend. Further efforts in reconstructing and collecting data from this early period are thus required in order to gain more knowledge about the long-term trend of the Sahel rainfall.

\section{b. Possible leading role of the AMO}

The results presented in this work show the important role of the Atlantic in driving the long humid Sahel period in the late nineteenth century. The lowfrequency variations of the Sahel rainfall have also been associated with Atlantic SSTA varying at decadal time scales by other works (e.g., Zhang and Delworth 2006; Knight et al. 2006; Ting et al. 2009, 2011; Martin and Thorncroft 2014; Martin et al. 2014). More specifically, these studies show the relationship between the Sahel rainfall variability and the AMO, whose associated pattern of SSTA has been identified as the dominant driver of the Sahel precipitation variations at decadal time scales compared to other basins (Mohino et al. 2011a). The AMO pattern of SSTA is characterized by a warming throughout the northern half of the

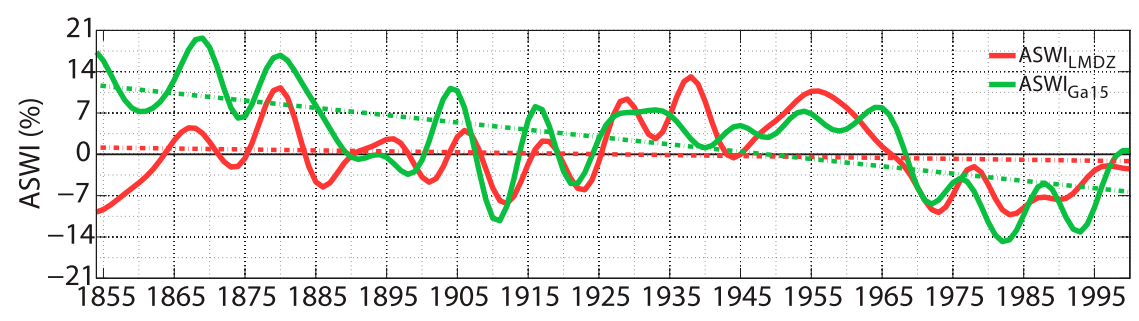

FIG. 10. Low-frequency ASWIs, normalized with respect to their climatology over 18542000, of the ensemble-mean LMDZ simulations (red) and GA15 (green). Hatched lines indicate the linear trend of the ASWIs over 1854-2000. The slopes are -0.016 and -0.124 ASWI units (\%) per year of the indices from the LMDZ simulations and GA15, respectively. 


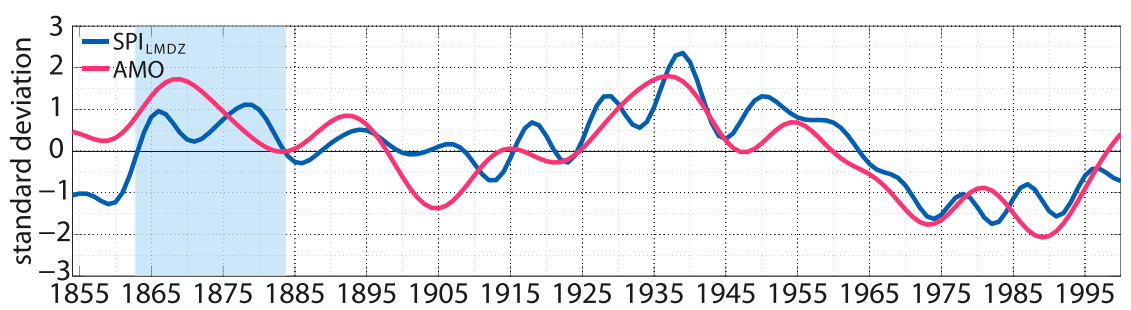

FIG. 11. Standardized low-frequency SPI (blue) of the ensemble-mean LMDZ simulations and AMO index (red) calculated from ERSST.v4 dataset. The light blue band highlights the late nineteenth-century rainy period (1863-83).

Atlantic basin during its positive phase (Sutton and Hodson 2005), similar to the mean SSTA of the late nineteenth century (Fig. 5b). In Fig. 11, the standardized low-frequency SPI from the simulations and the AMO index calculated from the ERSST.v4 dataset are represented together. Both indices are strongly correlated along the 1854-2000 period ( $R=0.72$, significant at a confidence level of $97 \%$ ) and the periods of positive (negative) rainfall anomalies in the Sahel roughly coincide with those of positive (negative) AMO phases. Focusing on the late nineteenth century, the wet period (1863-83) coincides with a positive AMO phase of large amplitude. Considering all this, it is reasonable to believe that during the late nineteenth century there was a connection between the AMO mode of variability and the Atlantic SSTA responsible for the forcing of the Sahel humid period.

\section{Conclusions}

In this study, the ability of the LMDZ to simulate the observed Sahel rainfall JAS climatology and low-frequency variability is shown. The model underestimates by $23 \%$ the observed precipitation over the Sahel and by one-third the amplitude of its variations. Yet, it successfully reproduces the atmospheric mechanisms driving the decadal shifts of the Sahel rainfall observed during the twentieth century.

Our results show that a decadal period of abundant Sahel precipitation in the late nineteenth century can be reproduced by forcing an AGCM with observational boundary conditions since 1854 . This result presents further evidence for the existence of such a rainy period. For the first time, we add information about the mechanisms involved in this long sequence of rainy years. The simulations show that, associated with a thermal gradient in the North Atlantic produced by a contrast of the SSTA near the coast of West Africa, there was a strong shift of the ITCZ over the Sahel concomitant with abundant precipitation with respect to climatology. A similar mechanism is simulated for the mid-twentieth-century decadal shift of precipitation. Therefore, it can be suggested that the late nineteenth-century decadal humid period may have occurred under similar circumstances to those driving the twentieth-century low-frequency variability. A set of sensitivity experiments reveals that the Atlantic SST led the Sahel rainfall variability at decadal time scales throughout 1854-1910. The origin of the late nineteenth-century rainy period may thus be attributed to the decadal variability of the Atlantic SST. More specifically, it could be related to the AMO. This result is in agreement with other works addressing the Sahel rainfall low-frequency variability during the twentieth century in observations and general circulation coupled models (e.g., Mohino et al. 2011a; Zhang and Delworth 2006; Hoerling et al. 2006; Knight et al. 2006; Ting et al. 2009, 2011; Martin and Thorncroft 2014; Martin et al. 2014).

In spite of the above results, there are still some unanswered questions regarding Sahel rainfall. On the one hand, our simulations show that this period was as rainy as the mid-twentieth-century one. NI12 rather suggests that there was moderate rainfall during the late nineteenth century and GA15 that the precipitation was even more abundant than during the observed mid-twentieth century. To clarify whether this discrepancy is significant, a thorough evaluation of the uncertainty of the observational indices presented in GA15 and NI12 associated with the data and the methods used for their reconstruction should be done. In turn, to accurately determine the precipitation amounts during the late nineteenth century, a greater effort to reconstruct or collect reliable observational precipitation data from this period is required. On the other hand, the trends during the 1854-2000 period of the ASWI long time series of GA15 and our simulations do not agree, which hinders our knowledge of the evolution of the WAM strength at longer-than-decadal time scales with our simulations and, by extension, the possible implications on the future projections of Sahel rainfall (Biasutti and Giannini 2006; Biasutti et al. 2008; Monerie et al. 2012; Biasutti 2013; Vizy et al. 2013).

Acknowledgments. The authors thank editor Dr. Barlow as well as Dr. Vellinga and the other 
anonymous reviewer for their duty and helpful comments. We are grateful to David Gallego for his comments and discussion on the ASWI. We acknowledge NOAA's National Centers for Environmental Information for providing the ERSST.v4 data (at http://www. esrl.noaa.gov/psd). We thank also the authors of GA15 and NI12 for making their time series freely available (at https://www.upo.es/investigacion/incite/dirindex.htm and ftp://ftp.ncdc.noaa.gov/pub/data/paleo/historical/africa, respectively). This work is the result of a 3-month stay of J.V. at LOCEAN/IPSL at Paris, France, funded by the Spanish Ministry of Economy and Competitiveness (MINECO) with support for short stays (EEBB-I-1610979-MINECO) within the scholarship he has been granted (BES-2013-063821-MINECO). The research leading to these results has received funding from the projects PREFACE (EUFP7/2007-2013 Grant Agreement 603521) and PRE-4CAST (CGL2017-86415-R). This work was granted access to the HPC resources of TGCC under the allocation 2015-017403 and 2016017403 made by GENCI. This study also benefited from the IPSL mesocenter facility, which is supported by CNRS, UPMC, Labex L-IPSL (funded by the ANR Grant ANR-10-LABX-0018 and by the European FP7 IS-ENES2 Grant 312979).

\section{REFERENCES}

Bader, J., and M. Latif, 2003: The impact of decadal-scale Indian Ocean sea surface temperature anomalies on Sahelian rainfall and the North Atlantic Oscillation. Geophys. Res. Lett., 30, 2169, https://doi.org/10.1029/2003GL018426.

Biasutti, M., 2013: Forced Sahel rainfall trends in the CMIP5 archive. J. Geophys. Res. Atmos., 118, 1613-1623, https://doi.org/ 10.1002/jgrd.50206.

— late 20th century forcings. Geophys. Res. Lett., 33, L11706, https://doi.org/10.1029/2006GL026067.

— I. M. Held, A. H. Sobel, and A. Giannini, 2008: SST forcings and Sahel rainfall variability in simulations of the twentieth and twenty-first centuries. J. Climate, 21, 3471-3486, https:// doi.org/10.1175/2007JCLI1896.1.

Caminade, C., and L. Terray, 2010: Twentieth century Sahel rainfall variability as simulated by the ARPEGE AGCM, and future changes. Climate Dyn., 35, 75-94, https://doi.org/ 10.1007/s00382-009-0545-4.

Cook, K. H., 1999: Generation of the African easterly jet and its role in determining West African precipitation. J. Climate, 12, 1165-1184, https://doi.org/10.1175/1520-0442(1999)012<1165: GOTAEJ $>2.0 . \mathrm{CO} ; 2$.

— , and E. K. Vizy, 2006: Coupled model simulations of the West African monsoon system: Twentieth- and twenty-first-century simulations. J. Climate, 19, 3681-3703, https://doi.org/10.1175/ JCLI3814.1.

Diamond, M. S., and R. Bennartz, 2015: Occurrence and trends of eastern and central Pacific El Niño in different reconstructed SST data sets. Geophys. Res. Lett., 42, 10375-10381, https:// doi.org/10.1002/2015GL066469.
Doblas-Reyes, F. J., and Coauthors, 2013: Initialized near-term regional climate change prediction. Nat. Commun., 4, 1715, https://doi.org/10.1038/ncomms2704.

Dufresne, J.-L., and Coauthors, 2013: Climate change projections using the IPSL-CM5 Earth System Model: From CMIP3 to CMIP5. Climate Dyn., 40, 2123-2165, https://doi.org/10.1007/ s00382-012-1636-1.

Ebisuzaki, W., 1997: A method to estimate the statistical significance of a correlation when the data are serially correlated. J. Climate, 10, 2147-2153, https://doi.org/10.1175/ 1520-0442(1997)010<2147:AMTETS > 2.0.CO;2.

Folland, C. K., T. N. Palmer, and D. E. Parker, 1986: Sahel rainfall and worldwide sea temperatures, 1901-85. Nature, 320, 602607, https://doi.org/10.1038/320602a0.

Gaetani, M., and E. Mohino, 2013: Decadal prediction of the Sahelian precipitation in CMIP5 simulations. J. Climate, 26, 7708-7719, https://doi.org/10.1175/JCLI-D-12-00635.1.

— C. Flamant, S. Bastin, S. Janicot, C. Lavaysse, F. Hourdin, P. Braconnot, and S. Bony, 2017: West African monsoon dynamics and precipitation: The competition between global SST warming and $\mathrm{CO}_{2}$ increase in CMIP5 idealized simulations. Climate Dyn., 48, 1353-1373, https://doi.org/10.1007/ s00382-016-3146-z.

Gallego, D., P. Ordóñez, P. Ribera, C. Peña-Ortiz, and R. GarcíaHerrera, 2015: An instrumental index of the West African monsoon back to the nineteenth century. Quart. J. Roy. Meteor. Soc., 141, 3166-3176, https://doi.org/10.1002/qj.2601.

García-Serrano, J., V. Guemas, and F. J. Doblas-Reyes, 2015: Added-value from initialization in predictions of Atlantic multi-decadal variability. Climate Dyn., 44, 2539-2555, https:// doi.org/10.1007/s00382-014-2370-7.

Giannini, A., R. Saravanan, and P. Chang, 2003: Oceanic forcing of Sahel rainfall on interannual to interdecadal time scales. Science, 302, 1027-1030, https://doi.org/10.1126/science.1089357.

— S. Salack, T. Lodoun, A. Ali, A. T. Gaye, and O. Ndiaye, 2013: A unifying view of climate change in the Sahel linking intra-seasonal, interannual and longer time scales. Environ. Res. Lett., 8, 024010, https://doi.org/10.1088/1748-9326/8/2/ 024010.

Gill, A. E., 1980: Some simple solutions for heat-induced tropical circulation. Quart. J. Roy. Meteor. Soc., 106, 447-462, https:// doi.org/10.1002/qj.49710644905.

Grist, J. P., and S. E. Nicholson, 2001: A study of the dynamic factors influencing the rainfall variability in the West African Sahel. J. Climate, 14, 1337-1359, https://doi.org/ 10.1175/1520-0442(2001)014<1337:ASOTDF>2.0.CO;2.

Hall, N. M. J., and P. Peyrillé, 2006: Dynamics of the West African monsoon. J. Phys. IV France, 139, 81-99, https://doi.org/ 10.1051/jp4:2006139007.

Harris, I., P. D. Jones, T. J. Osborn, and D. H. Lister, 2014: Updated high-resolution grids of monthly climatic observationsThe CRU TS3.10 dataset. Int. J. Climatol., 34, 623-642, https:// doi.org/10.1002/joc.3711.

Hoerling, M., J. Hurrell, J. Eischeid, and A. Phillips, 2006: Detection and attribution of twentieth-century northern and southern African rainfall change. J. Climate, 19, 3989-4008, https://doi.org/10.1175/JCLI3842.1.

Hourdin, F., and Coauthors, 2013: Impact of the LMDZ atmospheric grid configuration on the climate and sensitivity of the IPSL-CM5A coupled model. Climate Dyn., 40, 2167-2192, https://doi.org/10.1007/s00382-012-1411-3.

Huang, B., and Coauthors, 2015: Extended Reconstructed Sea Surface Temperature version 4 (ERSST.v4). Part I: Upgrades 
and intercomparisons. J. Climate, 28, 911-930, https://doi.org/ 10.1175/JCLI-D-14-00006.1.

— , and Coauthors, 2016: Further exploring and quantifying uncertainties for Extended Reconstructed Sea Surface Temperature (ERSST) version 4 (v4). J. Climate, 29, 3119-3142, https://doi.org/10.1175/JCLI-D-15-0430.1.

Ickowicz, A., V. Ancey, C. Corniaux, G. Duteurtre, R. PoccardChappuis, I. Touré, E. Vall, and A. Wane, 2012: Crop-livestock production systems in the Sahel-Increasing resilience for adaptation to climate change and preserving food security. Proc. Building Resilience for Adaptation to Climate Change in the Agriculture Sector, Rome, Italy, FAO-Organisation for Economic Cooperation and Development, 261-294, http://www. fao.org/docrep/017/i3084e/i3084e17.pdf.

Janicot, S., V. Moron, and B. Fontaine, 1996: Sahel droughts and ENSO dynamics. Geophys. Res. Lett., 23, 515-518, https:// doi.org/10.1029/96GL00246.

_- A. Harzallah, B. Fontaine, and V. Moron, 1998: West African monsoon dynamics and eastern equatorial Atlantic and Pacific SST anomalies (1970-88). J. Climate, 11, 1874-1882, https:// doi.org/10.1175/1520-0442-11.8.1874.

—, S. Trzaska, and I. Poccard, 2001: Summer Sahel-ENSO teleconnection and decadal time scale SST variations. Climate Dyn., 18, 303-320, https://doi.org/10.1007/s003820100172.

Joly, M., A. Voldoire, H. Douville, P. Terray, and J.-F. Royer, 2007: African monsoon teleconnections with tropical SSTs: Validation and evolution in a set of IPCC4 simulations. Climate Dyn., 29, 1-20, https://doi.org/10.1007/s00382-006-0215-8.

Kalnay, E., and Coauthors, 1996: The NCEP/NCAR 40-Year Reanalysis Project. Bull. Amer. Meteor. Soc., 77, 437-471, https:// doi.org/10.1175/1520-0477(1996)077<0437:TNYRP>2.0.CO;2.

Kennedy, J. J., 2014: A review of uncertainty in in situ measurements and data sets of sea surface temperature. Rev. Geophys., 52, 1-32, https://doi.org/10.1002/2013RG000434.

Kerr, R. A., 2000: A North Atlantic climate pacemaker for the centuries. Science, 288, 1984-1985, https://doi.org/10.1126/ science.288.5473.1984.

Knight, J. R., C. K. Folland, and A. A. Scaife, 2006: Climate impacts of the Atlantic multidecadal oscillation. Geophys. Res. Lett., 33, L17706, https://doi.org/10.1029/2006GL026242.

Krinner, G., and Coauthors, 2005: A dynamic global vegetation model for studies of the coupled atmosphere-biosphere system. Global Biogeochem. Cycles, 19, GB1015, https://doi.org/ 10.1029/2003GB002199.

Kucharski, F., F. Molteni, M. P. King, R. Farneti, I.-S. Kang, and L. Feudale, 2013: On the need of intermediate complexity general circulation models: A "SPEEDY" example. Bull. Amer. Meteor. Soc., 94, 25-30, https://doi.org/10.1175/BAMS-D-11-00238.1.

Latif, M., M. Collins, R. J. Stouffer, H. Pohlmann, and N. Keenlyside, 2004: The physical basis for prediction of Atlantic sector climate on decadal timescales. CLIVAR Exchanges, No. 31, International CLIVAR Project Office, Southampton, United Kingdom, 6-8.

Lebel, T., and A. Ali, 2009: Recent trends in the central and western Sahel rainfall regime (1990-2007). J. Hydrol., 375, 52 64, https://doi.org/10.1016/j.jhydrol.2008.11.030.

Liu, W., and Coauthors, 2015: Extended Reconstructed Sea Surface Temperature version 4 (ERSST.v4): Part II. Parametric and structural uncertainty estimations. J. Climate, 28, 931-951, https://doi.org/10.1175/JCLI-D-14-00007.1.

Martin, E. R., and C. D. Thorncroft, 2014: The impact of the AMO on the West African monsoon annual cycle. Quart. J. Roy. Meteor. Soc., 140, 31-46, https://doi.org/10.1002/qj.2107.
, and B. B. B. Booth, 2014: The multidecadal Atlantic SSTSahel rainfall teleconnection in CMIP5 simulations. J. Climate, 27, 784-806, https://doi.org/10.1175/JCLI-D-13-00242.1.

Matsuno, T., 1966: Quasi-geostrophic motions in the equatorial area. J. Meteor. Soc. Japan, 44, 25-43, https://doi.org/10.2151/ jmsj1965.44.1_25.

Meehl, G. A., and Coauthors, 2009: Decadal prediction: Can it be skillful? Bull. Amer. Meteor. Soc., 90, 1467-1486, https:// doi.org/10.1175/2009BAMS2778.1.

Mohino, E., S. Janicot, and J. Bader, 2011a: Sahel rainfall and decadal to multi-decadal sea surface temperature variability. Climate Dyn., 37, 419-440, https://doi.org/10.1007/s00382-010-0867-2.

—, B. Rodríguez-Fonseca, C. R. Mechoso, S. Gervois, P. Ruti, and F. Chauvin, 2011b: Impacts of the tropical Pacific/Indian Oceans on the seasonal cycle of the West African monsoon. J. Climate, 24, 3878-3891, https://doi.org/10.1175/ 2011JCLI3988.1.

, N. Keenlyside, and H. Pohlmann, 2016: Decadal prediction of Sahel rainfall: Where does the skill (or lack thereof) come from? Climate Dyn., 47, 3593-3612, https://doi.org/10.1007/ s00382-016-3416-9.

Monerie, P.-A., B. Fontaine, and P. Roucou, 2012: Expected future changes in the African monsoon between 2030 and 2070 using some CMIP3 and CMIP5 models under a medium-low RCP scenario. J. Geophys. Res., 117, D16111, https://doi.org/ 10.1029/2012JD017510.

Nicholson, S. E., D. Klotter, and A. K. Dezfuli, 2012: Spatial reconstruction of semi-quantitative precipitation fields over Africa during the nineteenth century from documentary evidence and gauge data. Quat. Res., 78, 13-23, https://doi.org/ 10.1016/j.yqres.2012.03.012.

Pomposi, C., Y. Kushnir, and A. Giannini, 2015: Moisture budget analysis of SST-driven decadal Sahel precipitation variability in the twentieth century. Climate Dyn., 44, 3303-3321, https:// doi.org/10.1007/s00382-014-2382-3.

$\mathrm{Pu}, \mathrm{B}$, and K. H. Cook, 2010: Dynamics of the west African westerly jet. J. Climate, 23, 6263-6276, https://doi.org/10.1175/ 2010JCLI3648.1.

Rayner, N. A., D. E. Parker, E. B. Horton, C. K. Folland, L. V. Alexander, D. P. Rowell, E. C. Kent, and A. Kaplan, 2003: Global analyses of sea surface temperature, sea ice, and night marine air temperature since the late nineteenth century. J. Geophys. Res., 108, 4407, https://doi.org/10.1029/ 2002JD002670.

Rodríguez-Fonseca, B., and Coauthors, 2011: Interannual and decadal SST-forced responses of the west African monsoon. Atmos. Sci. Lett., 12, 67-74, https://doi.org/10.1002/asl.308.

- and Coauthors, 2015: Variability and predictability of west African droughts: A review on the role of sea surface temperature anomalies. J. Climate, 28, 4034-4060, https://doi.org/ 10.1175/JCLI-D-14-00130.1.

Rowell, D. P., C. K. Folland, K. Maskell, J. A. Owen, and M. N. Ward, 1992: Modelling the influence of global sea surface temperatures on the variability and predictability of seasonal Sahel rainfall. Geophys. Res. Lett., 19, 905-908, https://doi.org/ 10.1029/92GL00939.

Sato, M., J. E. Hansen, M. P. McCormick, and J. B. Pollack, 1993: Stratospheric aerosol optical depths, 1850-1990. J. Geophys. Res., 98, 22 987-22 994, https://doi.org/10.1029/93JD02553.

Schneider, U., A. Becker, P. Finger, A. Meyer-Christoffer, B. Rudolf, and M. Ziese, 2016: GPCC full data reanalysis: Monthly land-surface precipitation from rain gauges built on GTS based and historic data, version 7.0. National Center for 
Atmospheric Research, accessed 1 June 2015, https://doi.org/ 10.5065/D6000072.

Sutton, R. T., and D. L. R. Hodson, 2005: North Atlantic forcing of North American and European summer climate. Science, 309, 115-118, https://doi.org/10.1126/science.1109496.

Thompson, D. W. J., J. M. Wallace, J. J. Kennedy, and P. D. Jones, 2010: An abrupt drop in Northern Hemisphere sea surface temperature around 1970. Nature, 467, 444-447, https:// doi.org/10.1038/nature09394.

Ting, M., Y. Kushnir, R. Seager, and C. Li, 2009: Forced and internal twentieth-century SST trends in the North Atlantic. J. Climate, 22, 1469-1481, https://doi.org/10.1175/2008JCLI2561.1.

,,$-- \ldots$, and _ 2011: Robust features of Atlantic multidecadal variability and its climate impacts. Geophys. Res. Lett., 38, L17705, https://doi.org/10.1029/2011GL048712.

Vellinga, M., M. Roberts, P. L. Vidale, M. S. Mizielinski, M.-E. Demory, R. Schiemann, J. Strachan, and C. Bain, 2016: Sahel decadal rainfall variability and the role of model horizontal resolution. Geophys. Res. Lett., 43, 326-333, https://doi.org/ 10.1002/2015GL066690.

Villamayor, J., and E. Mohino, 2015: Robust Sahel drought due to the interdecadal Pacific oscillation in CMIP5 simulations. Geophys. Res. Lett., 42, 1214-1222, https://doi.org/10.1002/ 2014 GL062473.

Vizy, E. K., K. H. Cook, J. Crétat, and N. Neupane, 2013: Projections of a wetter Sahel in the twenty-first century from global and regional models. J. Climate, 26, 4664-4687, https:// doi.org/10.1175/JCLI-D-12-00533.1.

Zeng, N., and J. D. Neelin, 1999: A land-atmosphere interaction theory for the tropical deforestation problem. J. Climate, $\mathbf{1 2}$, 857-872, https://doi.org/10.1175/1520-0442(1999)012<0857: ALAITF $>2.0 . \mathrm{CO} ; 2$.

Zhang, R., and T. L. Delworth, 2006: Impact of Atlantic multidecadal oscillations on India/Sahel rainfall and Atlantic hurricanes. Geophys. Res. Lett., 33, L17712, https://doi.org/ 10.1029/2006GL026267. 